\title{
A Silent Left Atrial Myxoma: A Rare Benign Cardiac Tumor
}

Rizwan Ali ${ }^{1}$, Arooj Tahir ${ }^{1}$, Muhammad Nadeem ${ }^{2}$, Syed B. Rizvi ${ }^{3}$

1. Internal Medicine, Rapides Regional Hospital, Alexandria, USA 2. Medicine, St Francis Medical Center 3. Cardiology Department, Rapides Regional Hospital, Alexandria, USA

Corresponding author: Rizwan Ali, rizwan_ali1113@yahoo.com

\begin{abstract}
Primary cardiac tumors are extremely rare. In one study, incidence was reported being less than $0.1 \%$. The purpose of this case report is to review different presentations of cardiac myxoma. A 34-year-old female with past medical history of drug abuse was brought into the emergency department (ED) after a motor vehicle collision. She was found to have multiple fractures with a hypodense mass in the left atrium. Further evaluation showed a left atrial myxoma. The patient underwent myxoma resection. The clinical appearance of myxoma varies from non-specific to life-threatening complications, such as stroke, acute heart failure, or even sudden death.
\end{abstract}

A surgical resection is the treatment of choice for cardiac myxomas.

Categories: Cardiac/Thoracic/Vascular Surgery, Cardiology, Neurology

Keywords: atrial myxoma, cardiac tumor

\section{Introduction}

Primary cardiac tumors are extremely rare [1]. In one study, incidence was reported less than $0.1 \%$ [2]. However, metastatic involvement of the heart is over 20 times more common and has been reported in an autopsy series in up to one in five patients dying of cancer [3]. Most heart tumors are benign. Nearly half of the benign heart tumors are myxomas [3]. Clinical appearance varies from non-specific to life-threatening complications, such as stroke, acute heart failure, or even sudden death [4-7]. Diagnosis and subsequent surgical treatment strongly depend on the clinical symptoms, but their extent does not correlate with the risk for serious complications [4].

\section{Case Presentation}

A 34-year-old female with a past medical history of drug abuse was brought into the emergency department (ED) after a motor vehicle collision; the patient was driving a jeep. The patient was confused in the ED.

Received 04/24/2018 Review began 04/25/2018 Review ended 04/27/2018 Published 04/30/2018

\section{() Copyright 2018}

Ali et al. This is an open access article distributed under the terms of the Creative Commons Attribution License CC-BY 3.0., which permits unrestricted use, distribution, and reproduction in any medium, provided the original author and source are credited. Initial imaging showed a closed distal right tibial fracture, open distal right fibular fracture, and a Grade 3 open right talus and calcaneus fracture. A computed tomography (CT) scan of the chest showed large hypodense mass within the left atrium of the heart (Figure 1). 


\section{Cureus}

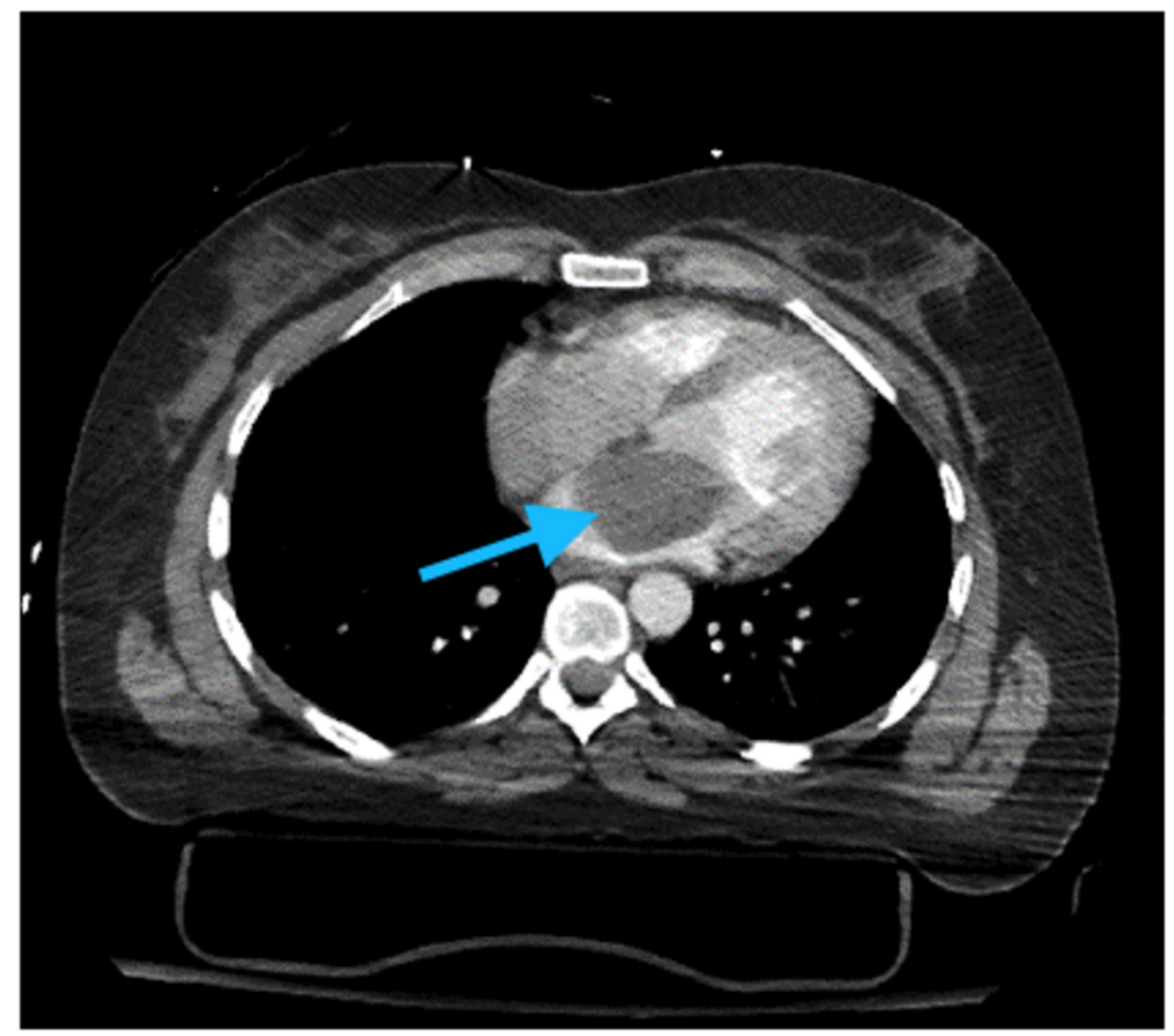

FIGURE 1: Computed tomography (CT) scan of Chest

Blue arrow pointing towards hypodense mass in left atrium

The patient was emergently taken to the operation theater for an open fracture repair. Initially, intramedullary nailing of the right tibial shaft fracture and incision and debridement of the open right fibular shaft, calcaneus, and talus fractures were done. Multiplanar right ankle spanning external fixation was applied. Wound vacuum-assisted closure (VAC) was also applied to the open wound. The patient subsequently underwent multiple debridements and was placed on broad-spectrum antibiotics but her wound got worse. After a detailed discussion with patient and family, it was decided to proceed with belowthe-knee amputation. The patient did develop a wound infection after amputation and continued on broadspectrum antibiotics.

For the left atrial mass, cardiology was consulted. The patient underwent transthoracic and transesophageal echocardiograms that confirmed the left atrial mass was consistent with a myxoma (Figures 2-3). 


\section{Cureus}

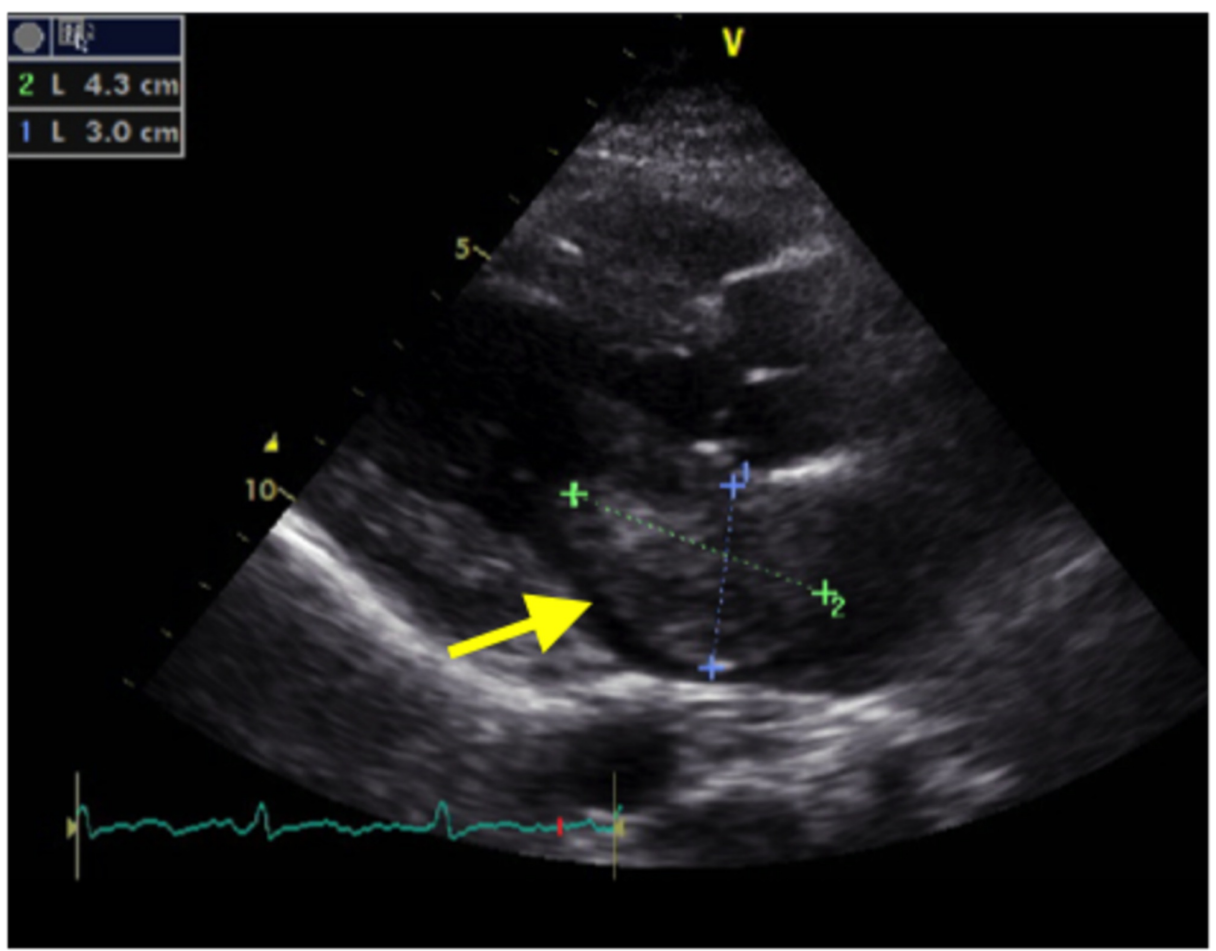

\section{FIGURE 2: Transthoracic echocardiogram}

Yellow arrow pointing towards left atrial mass

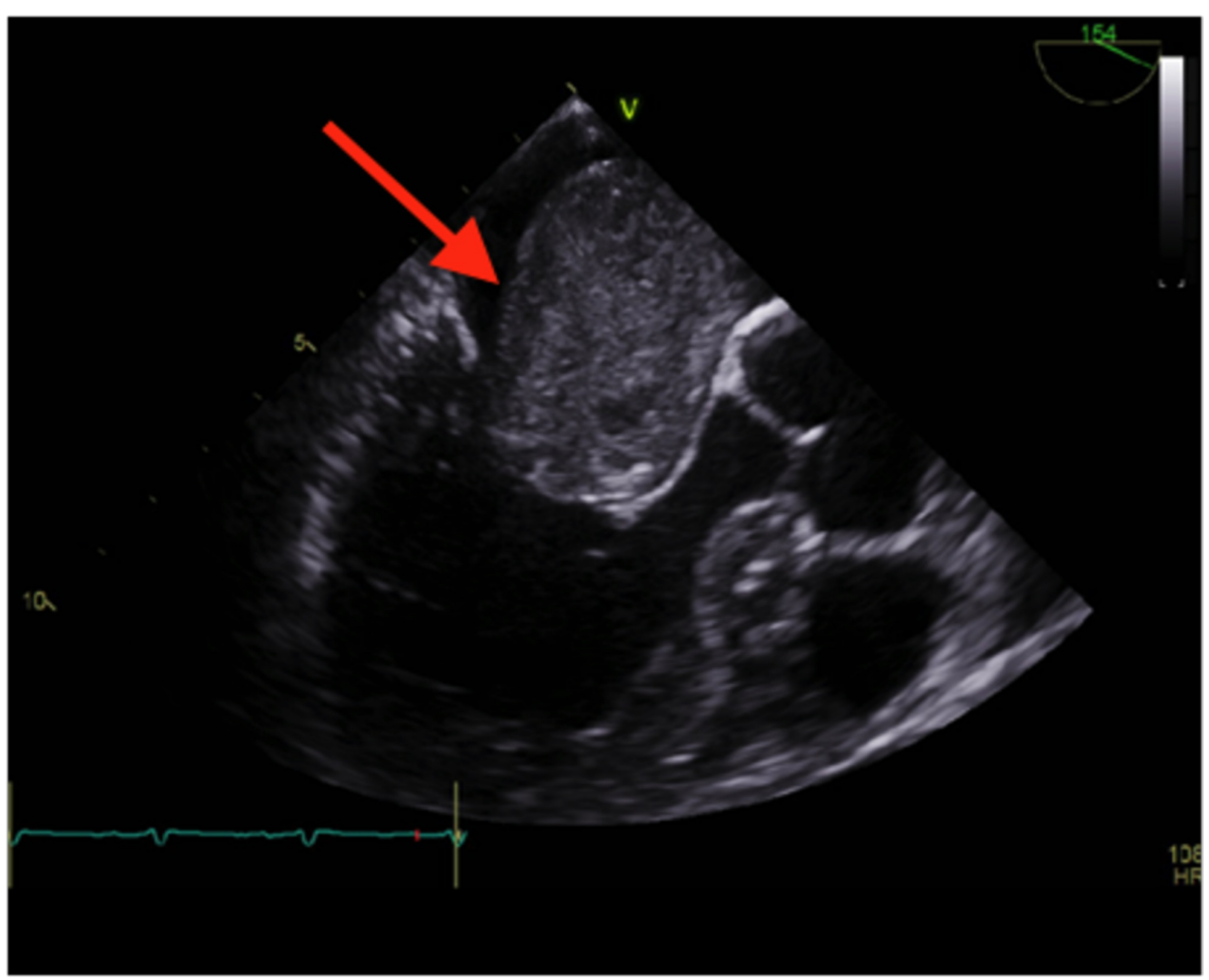

FIGURE 3: Transesophageal echocardiogram

Red arrow showing left atrial mass

Cardiovascular surgery was consulted for the resection of the left atrial myxoma. The patient underwent an uncomplicated resection of the left atrial mass. Pathology findings were consistent with a myxoma. The 


\section{Discussion}

Over $75 \%$ of primary cardiac tumors are benign [8-9]. Myxomas are the most common primary cardiac neoplasm. Histologically, these tumors are composed of scattered cells within a mucopolysaccharide stroma. Macroscopically, typical myxomas are pedunculated and gelatinous in consistency; the surface may be smooth, villous, or friable. Tumors vary widely in size, ranging from 1 to $15 \mathrm{~cm}$ in diameter, and weigh between 15 and 180 grams [10]. About 35\% of myxomas are friable or villous, and these tend to present with emboli. The cardiovascular manifestations depend upon the anatomic location of the tumor. Approximately $80 \%$ of myxomas originate in the left atrium, and most of the remainder are found in the right atrium [1112]. In addition to their cardiovascular effects, patients with myxomas frequently have constitutional symptoms (eg, weight loss, fever) and laboratory abnormalities that suggest the presence of a connective tissue disease [13]. According to one study, the incidence of cardiovascular symptoms was 67\% [14]. These symptoms consisted of mitral valve obstruction, electrocardiographic evidence of left atrial hypertrophy, auscultatory findings were found in $64 \%$, and the classic tumor plop was found in only $15 \%$. Systemic embolization was present in 29\%; $20 \%$ had neurologic deficits. The incidence of embolization was associated with smaller size $(<4.5 \mathrm{~cm})$ and softer tumors [15]. Constitutional symptoms (e.g., fever, weight loss) were seen in $34 \%$ of patients. Echocardiography is the simplest technique for such evaluation; cardiac magnetic resonance imaging (MRI) and ultrafast CT provide more detailed information. Tumors that occur from or invade the epicardial surface of the heart require coronary angiography preoperatively to define distortion of the coronary arteries and determine coronary blood supply to the tumor. Once a presumptive diagnosis of myxoma has been made on imaging studies, prompt resection is required because of the risk of embolization or cardiovascular complications, including sudden death [12, 16-17].

\section{Conclusions}

Over $75 \%$ of primary cardiac tumors are benign. Myxomas are the most common primary cardiac neoplasm. Myxomas can present with a wide range of symptoms, such as constitutional symptoms, cardiovascular symptoms (including obstruction and heart failure), and neurologic symptoms, such as embolization with infarction. Once one suspects myxomas, imaging studies (echocardiogram, transesophageal echocardiogram, chest CT, and MRI) can be done. Surgical resection is the treatment of the choice.

\section{Additional Information \\ Disclosures}

Human subjects: Consent was obtained by all participants in this study. Conflicts of interest: In compliance with the ICMJE uniform disclosure form, all authors declare the following: Payment/services info: All authors have declared that no financial support was received from any organization for the submitted work. Financial relationships: All authors have declared that they have no financial relationships at present or within the previous three years with any organizations that might have an interest in the submitted work. Other relationships: All authors have declared that there are no other relationships or activities that could appear to have influenced the submitted work.

\section{References}

1. Reynen K: Frequency of primary tumors of the heart. Am J Cardiol. 1996, 77:107. 10.1016/S00029149(97)89149-7

2. Lam KY, Dickens P, Chan AC: Tumors of the heart: A 20-year experience with a review of 12,485 consecutive autopsies. Arch Pathol Lab Med. 1993, 117:1027-31.

3. McAllister HA Jr, Fenoglio JJ Jr: Benign Tumors and Cysts of the Heart and Pericardium. Tumors of the Cardiovascular System. Atlas of Tumor Pathology. Second Series, Fa. McAllister HA Jr, Fenoglio JJ Jr (ed): Armed Forces Institute of Pathology, Washington DC; 1978. 1-20.

4. Cabrera H, Trindade e Silva LP, Gamboa C: Heart failure and syncope due to a giant atrial myxoma (Article in English, Portuguese). Rev Port Cardiol. 2010, 29:315-19.

5. Nishizaki Y, Yamagami S, Myojin M, et al.: A murmur-free giant myxoma discovered incidentally on abdominal ultrasonography. Intern Med. 2013, 52:2529-31. 10.2169/internalmedicine.52.0373

6. Maintz D, Gunia S, Baumgart P, et al.: Acute myocardial infarction as the first manifestation of left atrial myxoma. AJR Am J Roentgenol. 2004, 183:1838-39. 10.2214/ajr.183.6.01831838a

7. Akhundova A, Samedov F, Cincin A, et al.: Giant left atrial myxoma with dual coronary supply presenting with recurrent stroke. Herz. 2015, 40:318-20. 10.1007/s00059-013-3999-4

8. Shi L, Wu L, Fang H, et al.: Identification and clinical course of 166 pediatric cardiac tumors . Eur J Pediatr. 2017, 176:253-60. 10.1007/s00431-016-2833-4

9. Molina JE, Edwards JE, Ward HB: Primary cardiac tumors: experience at the University of Minnesota. Thorac Cardiovasc Surg. 1990, 38:183-91. 10.1055/s-2007-1014064

10. Pinede L, Duhaut P, Loire R: Clinical presentation of left atrial cardiac myxoma. A series of 112 consecutive cases. Medicine (Baltimore). 2001, 80:159-72. 10.1097/00005792-200105000-00002

11. ElBardissi AW, Dearani JA, Daly RC, et al.: Analysis of benign ventricular tumors: long-term outcome after resection. J Thorac Cardiovasc Surg. 2008, 135:1061-68. 10.1016/j.jtcvs.2007.10.048

12. Keeling IM, Oberwalder P, Anelli-Monti M, et al.: Cardiac myxomas: 24 years of experience in 49 patients . Eur J Cardiothorac Surg. 2002, 22:971-77. 10.1016/S1010-7940(02)00592-4 


\section{Cureus}

13. Maisch B: Immunology of cardiac tumors. Thorac Cardiovasc Surg. 1990, 38:157-63. 10.1055/s-20071014059

14. Pinede L, Duhaut P, Loire P: Clinical presentation of left atrial cardiac myxoma. A series of 112 consecutive cases. Medicine (Baltimore). 2001, 80:159-72. 10.1097/00005792-200105000-00002

15. Wang Z, Chen S, Zhu M, et al.: Risk prediction for emboli and recurrence of primary cardiac myxomas after resection. J Cardiothorac Surg. 2016, 11:22. 10.1186/s13019-016-0420-4

16. Selkane C, Amahzoune B, Chavanis N, et al.: Changing management of cardiac myxoma based on a series of 40 cases with long-term follow-up. Ann Thorac Surg. 2003, 76:1935-38. 10.1016/S0003-4975(03)01245-1

17. Cina SJ, Smialek JE, Burke AP, et al.: Primary cardiac tumors causing sudden death: a review of the literature. Am J Forensic Med Pathol. 1996, 17:271-81. 10.1097/00000433-199612000-00001 